\title{
Targeting Inflation by Forecast Feedback Rules in Small Open Economies*
}

\author{
Kai Leitemo ${ }^{\dagger}$ \\ Norwegian School of Management (BI)
}

January 2004

\begin{abstract}
We argue that inflation-targeting strategy in practice can be approximated with the interest rate responding to the unchanged-interest-rate forecast of inflation. We develop a method to derive unchanged-interest-rate forecasts in forward-looking models and evaluate the performance of the policy rule in an optimizing New Keynesian model due to Monacelli (2003) estimated on UK data. We find that the policy rule is less prone to generate a determinate rational expectations equilibrium if based on an unchanged interest rate compared to the rule-consistent forecast. The rule approximates the optimal commitment policy if the central bank attaches sufficient weight to inflation as opposed to output gap stabilization. The optimal forecast horizon is robustly close to one and a half year.
\end{abstract}

Keywords: Monetary policy, inflation targeting, feedback rules, small open economy. JEL codes: E61, E47, E43.

\footnotetext{
${ }^{*}$ This paper was partly written during a visit to the Carnegie Mellon University. I would like to thank Bennett T. McCallum and Carnegie Mellon for their hospitality. Comments from Andrew G. Haldane, Steinar Holden, Henrik Jensen, Bennett T. McCallum, Ragnar Nymoen, Asbjørn Rødseth, Øistein Røisland, Øystein Stephansen, Lars E.O. Svensson, and participants at seminars at the Department of Economics at the University of Oslo, Norges Bank, are gratefully acknowledged. I have benefited from adapted computer routines presented in Söderlind (1999). Remaining errors in this paper are entirely my own. Views and conclusions expressed are the responsibility of the author alone.

${ }^{\dagger}$ Address of the author: Department of Economics, Norwegian School of Management (BI), PO Box 580, N-1302 Sandvika, Norway. Tel: (+47) 67557477. Fax: (+47) 67557675. E-mail:kai.leitemo@bi.no
} 


\section{Introduction}

The arguably poor performance and robustness of fixed exchange rate systems and monetary targeting has resurrected the belief in more activist policy throughout the 1990s. Such activism is normally associated with the central bank's discretionary use of the interest rate in order to steer policy directly toward price stability, in the sense of low and stable inflation. Such a framework is often referred to as inflation targeting. Inflation targeting has been formally introduced in several countries, e.g., New Zealand, Canada, Sweden, the United Kingdom, Australia, Norway and Iceland, where the central banks have been given explicit targets for inflation and the instrument independence to set the interest rate so as to achieve the inflation target.

In the paper we shall interpret inflation targeting as a forecast-feedback rule for the interest rate in which the deviations of the forecast of inflation at some horizon from the target level is the prominent indicator. If the inflation forecast is above (below) the inflation target, the central bank sets a contractionary (expansionary) monetary policy stance, i.e., by setting interest rate above (below) its natural rate or moving the interest rate in steps towards this target rate.

With respect to the practical relevance of such rules, several central banks use such a procedure to guide policy. Sveriges Riksbank (1999) Inflation Report 3/99, p.58 states:

"Monetary policy is sometimes described with a simple rule of thumb: if the overall picture of inflation prospects (based on an unchanged repo rate) indicates that in twelve to twenty-four months' time inflation will deviate from the target, then the repo rate should normally be adjusted accordingly." (My italics)

Jansson and Vredin (2000) interprets the procedure of monetary policymaking at Sveriges Riksbank's as the use of UIF rules.

Svein Gjedrem, the Governor of the Central Bank of Norway, states

"The key rate is set on the basis of an overall assessment of the inflation outlook two years ahead. If it appears that inflation will be higher than 2 per cent with unchanged interest rates, the interest rate will be increased. If it appears that inflation will be lower than 2 per cent with unchanged interest rates, the interest rate will be reduced." (Gjedrem, 2002) (My italics)

Accordingly, there are reasons to believe that this procedure approximate how inflation targeting is carried out in practice. ${ }^{1}$ Although forecast-feedback rules have been analyzed previously (see discussion in the next section), they have been analyzed using rule-consistent forecast and not based upon an unchanged-interest-rate assumption, which according to the quotations seems to be the more relevant one.

\footnotetext{
${ }^{1}$ An alternative interpretation is offered by Leitemo (2000), where I study the effects of setting the interest rate so as to have the constant-interest-rate forecast of inflation equal to target at some given horizon.
} 
This paper presents a method of analyzing forecast-feedback rule that are based upon unchanged-interest-rate forecast of inflation in models with forward-looking behavior. ${ }^{2}$ Moreover, it provides an analysis of such rules in an empirical version of an optimizing open-economy New Keynesian model estimated on UK data, and contrast the results to the outcome of rules based upon policy-consistent forecasts of inflation.

We find that both strategies may be efficient in reducing a combination of inflation and output gap variability, although they generally stabilize inflation too much and the output gap too little. Both type of rules are prone to yield an indeterminate rational expectations equilibrium at long forecast horizons. The use of unchanged-interest-rate forecasts, however, makes the rules even more prone to indeterminacy. Although the interest rate assumption for the forecast have little effect if the forecast period is short, the assumption plays a crucial difference for horizons of six quarters and above, horizons lengths that seems relevant in practical monetary policymaking. The relevancy of the rule are underscored by the result that the optimal horizon is robustly close to six and seven quarters, a forecast horizon that corresponds closely to what is implemented in practice.

The remainder of the paper is organized as follows: Section 2 discusses the general characteristics of inflation targeting and the intuition behind the forecast-feedback inflation-targeting strategy. Section 3 presents a New Keynesian model of a small open economy due to Monacelli (2003) with both the domestic goods producers and firms importing goods from abroad experiencing rigidities in price setting. Section 4 presents the stabilization properties of the two types of policy rules and discuss the best choice of the forecast-feedback horizon. Finally, Section 5 provides a conclusion.

\section{The monetary policy framework}

In several papers, Svensson $(1997,1999 b, 2000)$ defines strict inflation targeting as a monetary policy strategy that discretionarily uses all available information in minimizing the unconditional variance of inflation around a given target level. Flexible inflation targeting means that the central bank also targets other variables, such as output, although to a lesser degree, by minimizing a weighted average of the unconditional variances of the target variables. Assuming that the central bank targets output and minimizes the change in the interest rate (i.e., interest-rate smoothing) in addition to the inflation rate itself, the period loss function is given by

$$
L_{t}=(1-\lambda)\left(\bar{\pi}_{t}-\pi^{*}\right)^{2}+\lambda y_{t}^{2}+\nu\left(\Delta i_{t}\right)^{2}
$$

where $\bar{\pi}$ is the four-quarter consumer price (CPI) inflation rate, $\pi^{*}$ is the inflation target, $y$ is the output gap, that is, the percentage deviation of actual output from the natural rate, $\Delta i$

\footnotetext{
${ }^{2}$ See also the discussion in Svensson (1999a) regarding the appropriateness of the unchanged-interest-rate inflation forecast as an indicator.
} 
is the quarterly change in the short-term interest rate, considered to be the policy instrument, $\lambda \in[0,1]$ and $\nu \geq 0$ are the relative weights attached by the monetary policymaker to output versus inflation stabilization objective and interest-rate smoothing respectively. The central bank's problem is then to minimize the unconditional expected loss, i.e.,

$$
\min E L_{t},
$$

subject to the model of the monetary policy transmission mechanism.

Although this definition of targeting has attractive theoretical properties, not least from an optimal control perspective, the practical implementation of policy using such a procedure may present several problems. First, there is little consensus on how the economy works. Two different descriptions of the economy may lead to mutually inconsistent policy recommendations. Indeed, optimal policy in a given model may produce a disastrous outcome in another. ${ }^{3}$ Another problem posed by optimal control is that, given that our models only use a (small) portion of available information, incorporating information that is external to the model in the policy decisions may be of considerable interest. In practice, however, such information is difficult to formalize. Integrating it with information provided by formal models, and exploiting it, may be difficult.

A third problem is related to the presence of forward-looking behavior in the model. The optimal policy with forward-looking behavior is in most circumstances time-inconsistent. That is, the policy requires an appropriate commitment today to policy tomorrow in order to influence agents expectations so as to get the best possible trade-off between policy targets both across and within periods. ${ }^{4}$ The central bank is normally not assumed to possess the ability to commit to complex policy rules.

There is therefore focus on achieving the goals of monetary policy through simpler and more transparent procedures, to which the central bank may be able to commit. Indeed, an alternative way of defining inflation targeting is that the instrument of the central bank responds to measures of inflation (forecast) deviation from the target level. In order to keep these two definitions separate, we follow Batini and Nelson (2001) in describing the alternative procedures of implementing inflation targeting as inflation forecast-feedback rules as opposed to the optimal control procedures. If $r$ is the policy interest rate, measured as a deviation from its unconditional (steady-state) value, a representation of the feedback rule is

$$
r_{t}=\rho_{r} r_{t-1}+\left(1-\rho_{r}\right) \beta_{\pi}\left[E_{t} \bar{\pi}_{t+H}-\pi^{*}\right]
$$

The interest rate as deviation from the equilibrium rate responds to the $H$ quarter forecast of

\footnotetext{
${ }^{3}$ Recently, Hansen and Sargent (2003) have developed optimal control methods for situations where the controller doubts the assumed model and wants policy to be robust to the assumed model deviating from the true (unknown) model.

${ }^{4}$ See Svensson and Woodford (1999) for a more detailed treatment.
} 
(four-quarter) CPI inflation rate $\left(E_{t} \bar{\pi}_{t+H}\right)$. We denote the rule in (3) as the policy-consistent forecast feedback rule, or PCF rule for short. $H$ is the forecast-feedback horizon. The forecast feedback horizon should be distinguished from the policy target horizon, i.e., the expected time before inflation has returned to its target level (see also Batini and Nelson, 2001). ${ }^{5}$

PCF rules have been discussed extensively in the literature. Batini and Haldane (1999) argues that the rule is "lag encompassing", i.e, takes account of the fact that monetary policy works with a lag on inflation by focussing on the inflation forecast. By responding to the forecast of inflation sufficiently ahead, it ensures that policy is responding preemptively to those inflationary shocks that monetary policy may indeed counteract. The policy rule includes the inflation forecast as an indicator and therefore embodies all relevant information about future information. The rule is therefore "information encompassing". Finally, they show that the rule within a small forward-looking macroeconomic model the rule does a good job in stabilizing both inflation and output (i.e., rule is "output encompassing") without causing too strong movements in the interest rate. Batini and Nelson (2001) evaluates the rule in both a vector autoregressive model (VAR) and a small forward-looking macroeconomic model and find that the optimized rule perform close to the optimal commitment policy. The optimal forecast-feedback horizon is however very dependent upon the model, being two quarters for the forward-looking model and as long as fifteen quarters for the VAR model. Levin et al. (2001) study the PCF rule in five models of the US economy and find although that the optimized rule does a good job in stabilizing inflation, the rule does a worse job in stabilizing output (i.e, rule is not output encompassing). However, by extending the rule to include the output gap as an indicator, an appropriately calibrated rule not only stabilizes output more efficiently, but also become more robust to model uncertainty, i.e., works well in all five models.

In this study we find that the PCF rule does a good job in stabilizing inflation appropriately, but lacks the output encompassing properties claimed by Batini and Haldane (1999), thus supporting and extending the result in Levin et al. (2001) to the open economy. The optimal forecast-feedback horizon is robustly found to be six or seven quarters, close to the forecastfeedback horizon used by many inflation-targeting central banks.

If the horizon employed in producing the inflation forecast is longer than the control lag of the policy instrument, the forecast depends not only on the present stance of policy, but also on the future policy stance. There is hence a need for conditioning the forecast on a particular policy over the forecast-feedback horizon. The usual way to proceed is to condition on expected policy, i.e., produce a rule-consistent forecast of inflation. This is the approach taken by Batini and Haldane (1999), Batini and Nelson (2001) and Levin et al. (2001). Although this assumption ensures consistency, it may be somewhat unrealistic from a practical point of view. Forecasts

\footnotetext{
${ }^{5}$ The forecast-feedback horizon and the policy target horizon will only coincide when the length of the horizon is such that inflation will have returned to the target rate of inflation without any reactions by the monetary authority to the state of the economy, i.e., the interest rate is kept constant at its equilibrium value. In this case, $\pi_{t+h \mid t}=\pi^{*}=\pi^{e}$, and $i_{t}=i^{e}=r^{e}+\pi^{e}$, where superscript $e$ denotes an equilibrium value and $r$ is the short-term real interest rate.
} 
that are based on assumptions about specific future interest rate changes may be of little guidance to the interest rate decision body that may have a hard time just deciding about the present interest-rate stance. Svensson (1999a) argues that the forecast should be based on an unchanged interest rate. This allows the decision body to focus on current interest rate setting, and not having to form expectations about future interest rate decisions. Moreover, Svensson argues that it may be easier to incorporate outside-of-the-model information under such a procedure. The reason being that such information may take the form of the policymakers' judgment regarding non-modelled factors that influence the forecast of inflation, given that the policy stance remains unchanged.

Equation (3) may be reformulated along these lines to

$$
r_{t}=\rho_{r} r_{t-1}+\left(1-\rho_{r}\right) \beta_{\pi}\left[E_{t} \pi\left(\bar{r}_{t-1}\right)_{t+H}-\pi^{*}\right]
$$

where $E_{t} \bar{\pi}\left(\bar{i}_{t-1}\right)_{t+h}$ is the four-quarter CPI inflation forecast contingent on the interest rate remaining unchanged over the forecast-feedback horizon, equal to the rate in the previous period. Equation (4) can be denoted an unchanged-interest-rate inflation forecast-feedback rule, or UIF rule, for short. Rudebusch and Svensson (1999) examine interest rate rules where the interest rate reacts to the unchanged-interest-rate forecast of inflation in a backward-looking model of the U.S. economy and find that it performs close to the optimal policy.

\subsection{Constructing unchanged-interest-rate forecasts in forward-looking models}

This paper is the first to consider UIF rules in forward-looking models. The construction of conditional forecasts in forward-looking models require some comments. Forward-looking variables are at least partially determined by expectations about future actions, by some or all of the agents in the model. Since the forecast of inflation is the prominent indicator for the interest rate, the unchanged-interest-rate assumption will influence current and expected future interest-rate setting and therefore the forward-looking variables.

It is important to note that the unchanged-interest-rate assumption is merely an assumption that is invoked in the construction the forecast, not the rationally expected interest-rate setting with a UIF rule. In order to see this, consider the following example where we assume for simplicity that there is no structural interest-rate inertia, setting $\rho_{r}=0$. Moreover, assume that in period 1, an unchanged-interest-rate produces a inflation forecast that is above the inflation target, and the interest rate is therefore set above its steady-state value (of 0 ). In period 2 , the interest rate is changed if the new unchanged-interest-rate forecast deviation from the inflation target is different from that in the previous period. The interest rate only remains unchanged in the rare cases where the deviation is unchanged. Rational agents will therefore normally expect the unchanged-interest-rate assumption not to be met, but instead base their interest rate expectations about the policy implications of the rule. 
In a setting with symmetric information between the private sector and the policymaker, the private sector will simultaneously predict the policymaker's interest-rate response, as the policymaker predicts private-sector behavior, and interest-rate setting will in itself not cause an 'jump' in the forward-looking variables since it does not reveal any new information about the future. In designing the unchanged-interest-rate forecast of inflation, the (equilibrium values of the) forward-looking variables are therefore treated as predetermined. Note, however, that the equilibrium value of the forward-looking variables depend on the rationally expected future policy, not on the unchanged-interest-rate assumption. Hence, the unchanged-interest-rate forecasts are partly based on the policy rule itself and partly the unchanged-interest-rate assumption. Appendix A gives a formal treatment of how to incorporate UIF rule in forward-looking models with a state-space representation. ${ }^{6}$

\section{A New Keynesian model with imperfect exchange-rate pass-through}

In order to evaluate the inflation forecast-feedback rules we need a model of the economy. Recently, Monacelli (2003) has developed a model of a small open economy with optimizing agents in a setting with imperfect pass-through of the exchange rate onto the domestic currency price of foreign goods. The economy is populated by infinitely-lived households, consuming domestic and imported goods. The domestic firms produce a differentiated good and set their prices in a monopolistic competitive market. Similarly, importing firms buy their goods at world market prices and set the domestic-currency price of their goods in the domestic market. All firms are subject to Calvo (1983) type price setting that gives rise to a supply functions in the familiar form of forward-looking Phillips curve.

In the following, we give a brief presentation of the log-linearized version of the Monacelli model, with coefficient being policy-invariant functions of utility and technology parameters. For details, we refer the reader to Monacelli (2003).

Domestic aggregate supply is described by a New Keynesian Phillips curve of the form

$$
\pi_{t}^{H}=\beta E_{t} \pi_{t+1}^{H}+\kappa_{x} x_{t}+\kappa_{\psi} \psi_{t}^{F}
$$

where $\pi_{t}^{H} \equiv p_{t}^{H}-p_{t-1}^{H}$ is the rate of price inflation on goods produced domestically in period $t$, $x_{t}$ is the output gap, the percentage deviations of output from the flexible-price level of output and $\psi_{F, t} \equiv e_{t}+p_{t}^{*}-p_{F, t}$ is the percentage deviations of world price on foreign goods (i.e., $e_{t}+p_{t}^{*}$, where $e_{t}$ is the nominal exchange rate and $p_{t}^{*}$ is the foreign currency price of the foreign goods) from the domestic price on the foreign goods, denoted as the law-of-one-price (LOP) gap.

CPI inflation, $\pi_{t} \equiv p_{t}-p_{t-1}$, is a weighted average of domestic and foreign goods price

\footnotetext{
${ }^{6}$ Appendix B shows similarly how to incorporate PCF rule in a state-space representation of a forward-looking model.
} 
inflation,

$$
\begin{aligned}
\pi_{t} & =(1-\gamma) \pi_{t}^{H}+\gamma \pi_{t}^{F} \\
& =\pi_{t}^{H}+\gamma \Delta s_{t}
\end{aligned}
$$

where $\pi_{t}^{F} \equiv p_{t}^{F}-p_{t-1}^{F}$ is the rate of price inflation on imported goods and $\Delta s_{t} \equiv \pi_{t}^{F}-\pi_{t}^{H}$ is the rate of change in the terms of trade.

The imported goods supply curve is given by

$$
\pi_{t}^{F}=\beta E_{t} \pi_{t+1}^{F}+\lambda_{\psi} \psi_{t}^{F}
$$

The uncovered interest parity condition determines the nominal exchange rate, i.e.,

$$
e_{t}=E_{t} e_{t+1}-r_{t}+r_{t}^{*}
$$

where $r_{t}$ and $r_{t}^{*}$ are the risk-free domestic and foreign short-term nominal interest rates, respectively.

It is useful to point out that there is a definitional correspondence between the real exchange rate, $q_{t} \equiv e_{t}+p_{t}^{*}-p_{t}$, and the law-of-one-price gap, which is given by

$$
\begin{aligned}
\psi_{t}^{F} & \equiv e_{t}+p_{t}^{*}-p_{t}^{F}, \\
& =e_{t}+p_{t}^{*}-p_{t}-(1-\gamma)\left(p_{t}^{F}-p_{t}^{H}\right), \\
& =q_{t}-(1-\gamma) s_{t} .
\end{aligned}
$$

The demand for the (aggregated) domestic product, represented by the output gap, is given by

$$
x_{t}=E_{t} x_{t+1}-\chi\left(r_{t}-E_{t} \pi_{t}^{H}-\overline{r r}_{t}\right)+\delta E_{t}\left(\Delta \psi_{t+1}^{F}\right) .
$$

where the natural real interest rate, $\overline{r r}_{t}$, is given by

$$
\overline{r r}_{t} \equiv \phi E_{t} \Delta y_{t+1}^{*}+\theta z_{t}
$$

where $z$ is a domestic productivity shock and $y^{*}$ is world output.

\subsection{The empirical specification}

Although the above theoretical framework gives a canonical representation of private sector behavior in an economy where goods prices are subject to stickiness, the framework abstracts from possible information and implementation lags that may give rise to gradual adjustment present in the real world. Such inertial responses may be rationalized and explained by agents 
using rule-of-thumb pricing (Christiano et al., 2001), and consumers being subject to habit formation (Fuhrer, 2000). For these reasons, we follow Rudebusch (2002a,b) in allowing data to determine the exact structure of leads and lags in the economy. Moreover, we allow the equations to be subject to stochastic white-noise error terms, and all equations are estimated with a (non-reported) intercept term. We estimate the model on UK data obtained from either the national accounts or the IMF and OECD databases.

The Phillips curve for domestic inflation is estimated as

$$
\pi_{t+1}^{H}=\mu_{H} E_{t} \bar{\pi}_{t+4}^{H}+\left(1-\mu_{H}\right) \sum_{j=0}^{3} \alpha_{j} \pi_{t-j}^{H}+\kappa_{x} E_{t} x_{t+1}+\kappa_{\psi} E_{t} \psi_{t+1}^{F}+\varepsilon_{t+1},
$$

where $\pi_{t+1}^{H}$ is the quarterly percentage increase in the GDP deflator measured as an annual rate, $\bar{\pi}_{t} \equiv \frac{1}{4} \sum_{j=0}^{3} \pi_{t-j}$ is the four-quarter inflation rate. The estimation period is $1980 Q 1-2001 Q 4$ and the model is estimated by GMM. We impose dynamic homogeneity, i.e., $\sum_{j=0}^{3} \alpha_{j}=1$. The LOP gap has been computed according to equation (5), using detrended effective real exchange rate and terms of trade. ${ }^{7}$ The terms of trade was derived as the percentage deviation between the imported goods prices and the domestic price level. The share of imported goods in the consumer basket is set at $\gamma=0.25 .^{8}$ The output gap is detrended log GDP. As instruments we used eight lags of the quarterly domestic inflation rate, fours lags of the deviations from the law of one price, the output gap, UK 3-month interest rate, US federal funds rate and OECD output gap. The preferred model is given as

$$
\begin{aligned}
\pi_{t+1}^{H}= & \underset{(0.08)}{0.58} E_{t} \bar{\pi}_{t+4}^{H}+\underset{(-)}{0.42}\left(-\underset{(0.16)}{0.39} \pi_{t}^{H}+\underset{(0.06)}{0.22} \pi_{t-1}^{H}+\underset{(0.11)}{0.72} \pi_{t-2}^{H}+\underset{(-)}{0.45} \pi_{t-3}^{H}\right) \\
& +\underset{(0.13)}{0.28} E_{t} x_{t+1}+\underset{(0.06)}{0.04} E_{t} \psi_{t+1}^{F}+\varepsilon_{t+1} . \\
& \bar{R}^{2}=0.67 \quad \sigma=0.02 \quad D W=1.60
\end{aligned}
$$

Imported goods price inflation is estimated according to the form

$$
\pi_{t+1}^{F}=\mu_{F} E_{t} \bar{\pi}_{t+4}^{F}+\left(1-\mu_{F}\right) \sum_{j=0}^{3} \varkappa_{j} \pi_{t-j}^{F}+\omega_{\psi} E_{t} \psi_{t+1}^{F}+v_{t+1},
$$

where $\pi^{F}$ is quarterly imported good price inflation measured as an annual rate, and $\bar{\pi}_{t}^{F} \equiv$ $\frac{1}{4} \sum_{j=0}^{3} \pi_{t-j}^{F}$. The model was estimated over the period 1980Q1-2001Q4 using GMM. The instruments are eight lags of imported goods price inflation and fours lags of the LOP gap, the output gap, UK 3-month interest rate, US federal funds rate and OECD output gap. The

\footnotetext{
${ }^{7}$ All detrending was performed using a HP-filter with the smoothing parameters set at 1600.

${ }^{8}$ This corresponds to the value used in Batini and Haldane (1999) and is reasonable for a small open economy.
} 
preferred model is then given as

$$
\begin{aligned}
\pi_{t+1}^{F}= & \underset{(0.05)}{0.78} E_{t} \bar{\pi}_{t+4}^{F}+\underset{(-)}{0.22} \underset{(0.19)}{\left.\underset{(0.11}{1.1} \pi_{t}^{F}-\underset{(-)}{0.111 \pi_{t-3}^{F}}\right)}+\underset{(0.10)}{0.56 E_{t}} \psi_{t+1}^{F}+v_{t+1} . \\
& \bar{R}^{2}=0.46 \quad \sigma=0.06 \quad D W=1.92
\end{aligned}
$$

The output gap is estimated as

$$
\begin{aligned}
x_{t+1}= & \mu_{x} E_{t} x_{t+2}+\left(1-\mu_{x}\right)\left(\eta x_{t}+(1-\eta) x_{t-1}\right)-\chi\left(r_{t}-E_{t} \bar{\pi}_{t+3}^{H}\right) \\
& +\delta E_{t} \Delta \psi_{t+1}^{F}+\phi E_{t} \Delta y_{t+1}^{*}+u_{t+1} .
\end{aligned}
$$

where $y^{*}$ is foreign output which is approximated by the OECD output gap. The instruments used were four lags of quarterly domestic inflation rate, the LOP gap, the output gap, UK 3 -month interest rate, US federal funds rate and growth rate of OECD GDP.

$$
\begin{aligned}
x_{t+1}= & \underset{(0.04)}{0.53} E_{t} x_{t+2}+\underset{(-)}{0.47}\left(\underset{(0.08)}{1.36} x_{t}-\underset{(-)}{0.36} x_{t-1}\right)-\underset{(0.01)}{0.07}\left(r_{t}-E_{t} \bar{\pi}_{t+3}^{H}\right) \\
& +\underset{(0.01)}{0.11} E_{t} \Delta \psi_{t+1}^{F}+\underset{(0.07)}{0.25} E_{t} \Delta y_{t+1}^{*}+u_{t+1} . \\
& \bar{R}^{2}=0.90 \quad \sigma=0.004 \quad D W=2.05
\end{aligned}
$$

It is worth noting that we find that both price setting and demand determination seem to include both forward-looking and backward-looking elements in a significant way. This confirms most of the results in the literature.

The uncovered interest parity condition was estimated assuming that the unobserved riskfree foreign real interest rate can be approximated with an autoregressive process. Unconstrained estimation yields

$$
\begin{aligned}
q_{t}= & \underset{(0.001)}{0.997} E_{t} q_{t+1}-\underset{(0.58)}{0.965}\left(r_{q, t}-E_{t} \pi_{q, t+1}\right)+r r_{q, t}^{*} \\
r r_{q, t}^{*}= & \underset{r}{0.34} r r_{q, t-1}^{*}+w_{t} \\
& (0.07) \\
& \bar{R}^{2}=0.87 \quad \sigma=0.034 \quad D W=2.15
\end{aligned}
$$

where $r_{q, t} \equiv \frac{1}{4} r_{t}, \pi_{q, t} \equiv \frac{1}{4} \pi_{t}$ and $r r_{q, t}^{*} \equiv \frac{1}{4} r r_{t}^{*}$ are the UK 3-month interest rate, quarterly CPI inflation rate, foreign real interest rate, respectively, all (approximately) measured as quarterly rates. The instruments are four lags of the real effective exchange rate, UK 3-month interest rate, US federal funds rate, quarterly CPI inflation rate and OECD output gap. We found that the residuals were modelled well by an $\mathrm{AR}(1)$ process as additional lags where insignificant. Although imprecisely estimated, the interest rate term has a coefficient that is almost equal to the theoretical expected value of unity. Similarly, the coefficient on the forward exchange rate 
term is also almost 1, also as expected from theory. By constraining the coefficients to 1, the preferred model is given by

$$
\begin{aligned}
q_{t}= & E_{t} q_{t+1}-\left(r_{q, t}-E_{t} \pi_{q, t+1}\right)+r r_{q, t}^{*} \\
r r_{q, t}^{*}= & \underset{(0.07)}{0.50 r r_{q, t-1}^{*}}+\underset{(0.06)}{0.19} r r_{q, t-2}^{*}+\underset{(0.04)}{0.11} r r_{q, t-3}^{*}+w_{t} \\
& \bar{R}^{2}=0.85 \quad \sigma=0.037 \quad D W=2.12
\end{aligned}
$$

and the foreign real interest rate is approximated best by an $\mathrm{AR}(3)$ process.

Finally, we model the OECD output growth according to an autoregressive process as

$$
\begin{aligned}
\Delta y_{t}^{*}= & \underset{(0.07)}{0.51 \Delta y_{t-1}^{*}+\xi_{t}} \\
& \bar{R}^{2}=0.25 \quad \sigma=0.005 \quad D W=2.14
\end{aligned}
$$

\section{Policy analysis}

In this section we start by giving a description of the transmission mechanism of the model by considering the a disinflationary experiment, unexpectedly lowering the inflation target by once percentage point, assuming that policy is implemented through a forecast-feedback rule. We then consider the configuration of the rule parameters from two perspectives. First, we infer what configurations (if any) of the rule yield a determinate rational expectations equilibrium. Second, we infer among the rule configurations which yield a rational expectations equilibrium whether the rule may come close to replicating the outcome of the optimal commitment policy.

\subsection{A disinflationary experiment}

Figure 1 shows the response of key variables to an unexpected reduction in the inflation target for the UIF and PCF rules. We assume a forecast feedback horizon of eight quarters, which seems reasonable given the statements by the central bankers quoted in the introduction. Note that variables are measured relative to their new steady-state values. We assume that the policymaker set $\rho=0.95$ and $\beta=6.25$ in case of the UIF rule and $\rho=0.8$ and $\beta=10$ for the PCF rules. 9

The announcement of the a lower inflation target makes private agents reduce their inflation expectations which lead to an increase in the real interest rate. The unchanged-interest-rate brings about an undershooting of the inflation target at the relevant horizon and the nominal interest rate is gradually lowered. Lower expectations about future inflation implies expectations of a lower price level. Thus the nominal exchange rate appreciates immediately and depreciate toward its new steady-state growth path. As there are expectations of future positive real

\footnotetext{
${ }^{9}$ Section 4.3 will show that these coefficients determine the rational expectations equilibrium and produce the least loss with the given forecast-feedback horizon.
} 
Figure 1

The response to an unexpected reduction in the inflation target with $H=8$.

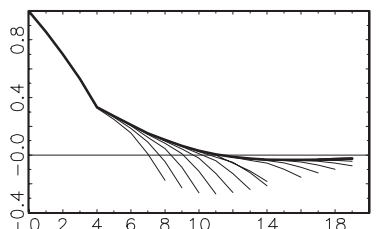

Nominat and reat interest rote

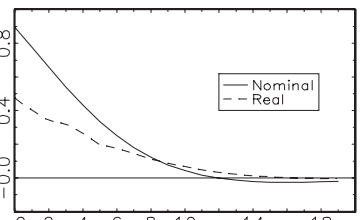

(a) The UIF rule

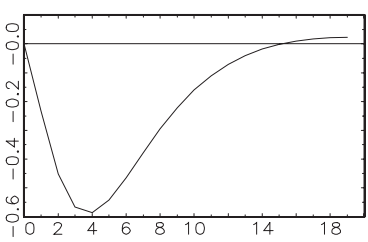

Real exchange rate

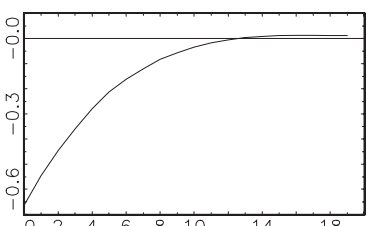

(b) The PCF rule
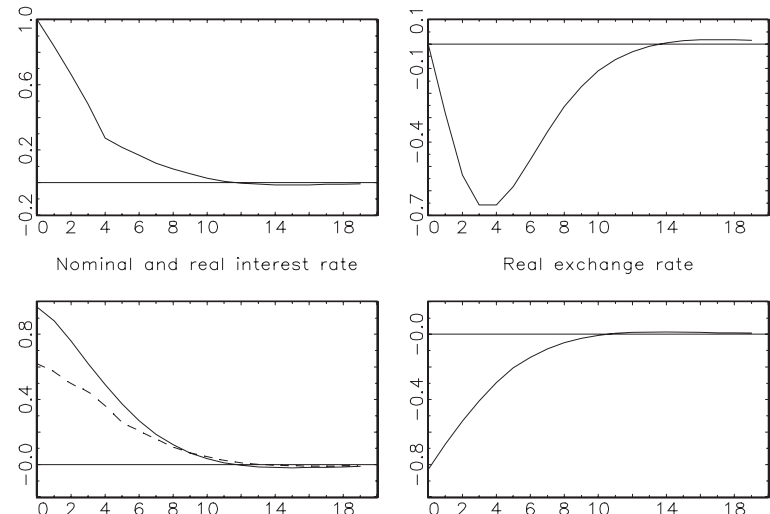

Real exchange rote

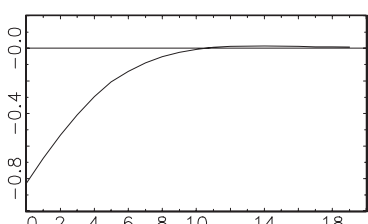

interest rate (differentials), the real exchange rate appreciates at the time of announcement and then depreciates at a rate equal to the real interest rate differential. The increase in the real interest rate and the temporary real appreciation lower the output gap over a period of three years. Also after three years, CPI inflation is approximately back on target. Figure 4.2(b) shows that the responses under a PCF rule are quite similar, albeit somewhat stronger as the interest rate reacts somewhat more aggressively to the disinflation shock.

The similarity between the responses is dependent on the coefficients being optimally selected. Figure $\mathrm{C} 1$ in the appendix shows the response under the PCF rule with the coefficient for the UIF rule, stated above. In this regard, the implied responses from the two rules are quite different at a horizon of eight quarters. In the stated case, the PCF rule causes overstabilization and cyclical evolvement in the model.

The disinflation experiment illustrates that the forecast-feedback horizon may deviate substantially for the policy target horizon; it always takes longer time than the forecast-feedback horizon to bring inflation back to its target in steady state. The exact size of the deviation is, however, dependent on the configuration of the rule as well as the type of shock the economy is subject to.

\subsection{Determinacy}

We now consider the issue of whether the forecast feedback rules determine the rational expectations (RE) equilibrium. Blanchard and Kahn (1980) show that in order for the RE equilibrium to be determined, we need that there are as many unstable eigenvalues as there are forwardlooking variables in the model. This turns out to be an important issue for the forecast-feedback rules as this requirement is not met for an a large set of parameter values. Figures 2 and 3 show the configurations of parameters in the rule that determines the RE equilibrium, denoted by a value of unity, for the UIF rule and PCF rules, respectively. There are at least three important 


\section{Figure 2}

Parameter determinacy region for the UIF rule at different forecast-feedback horizons.

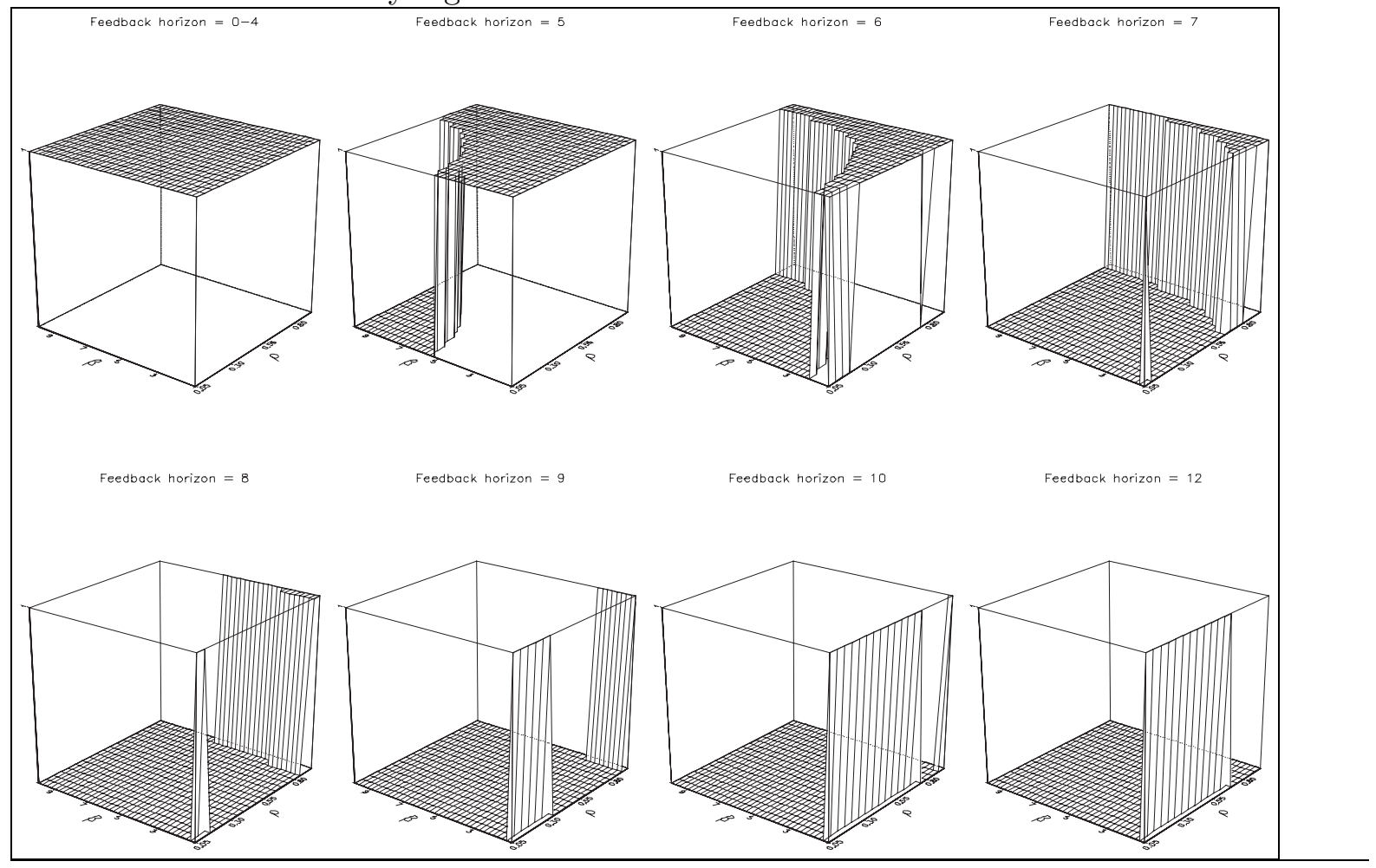

observations to be made.

First, the length of the forecast-feedback horizon is important for determinacy. We consider horizons between zero and twelve quarters and the the region of determinacy decreases as the horizon increases. The requirement for determinacy is often stated as the Taylor principle (Woodford, 2001) which means that the nominal interest rate needs to react sufficiently to increased inflation expectations to raise the real interest rate. Note that the real interest rate is determined by next-period inflation expectations and a reaction to inflation expectations in the more distant future may not suffice to raise the real interest rate. Hence, a long forecast-feedback horizon may fail to determine the RE equilibrium.

Second, a higher value of $\beta_{\pi}$ is likely to produce indeterminacy. The reason is that the rule causes inflation to undershoot the target at the relevant horizon and a strong response is likely to lower nominal interest rate and therefore real rates in the event of an inflationary shock. A larger value of $\rho_{r}$ reduces the response to future inflation for a given choice of $\beta_{\pi}$ and therefore contributes to determinacy.

Third, the region for determinacy is smaller for the UIF rule than for the PCF rule. Indeterminacy is evident for some choices of $\left(\beta_{\pi}, \rho_{r}\right)$ starting at a horizon of five quarters with regards to the UIF rule, and at six quarters for the PCF rule. In general, the region of determinacy seems larger for the PCF rule than for the UIF rule. 


\section{Figure 3}

Parameter determinacy region for the PCF rule at different forecast feedback horizons.

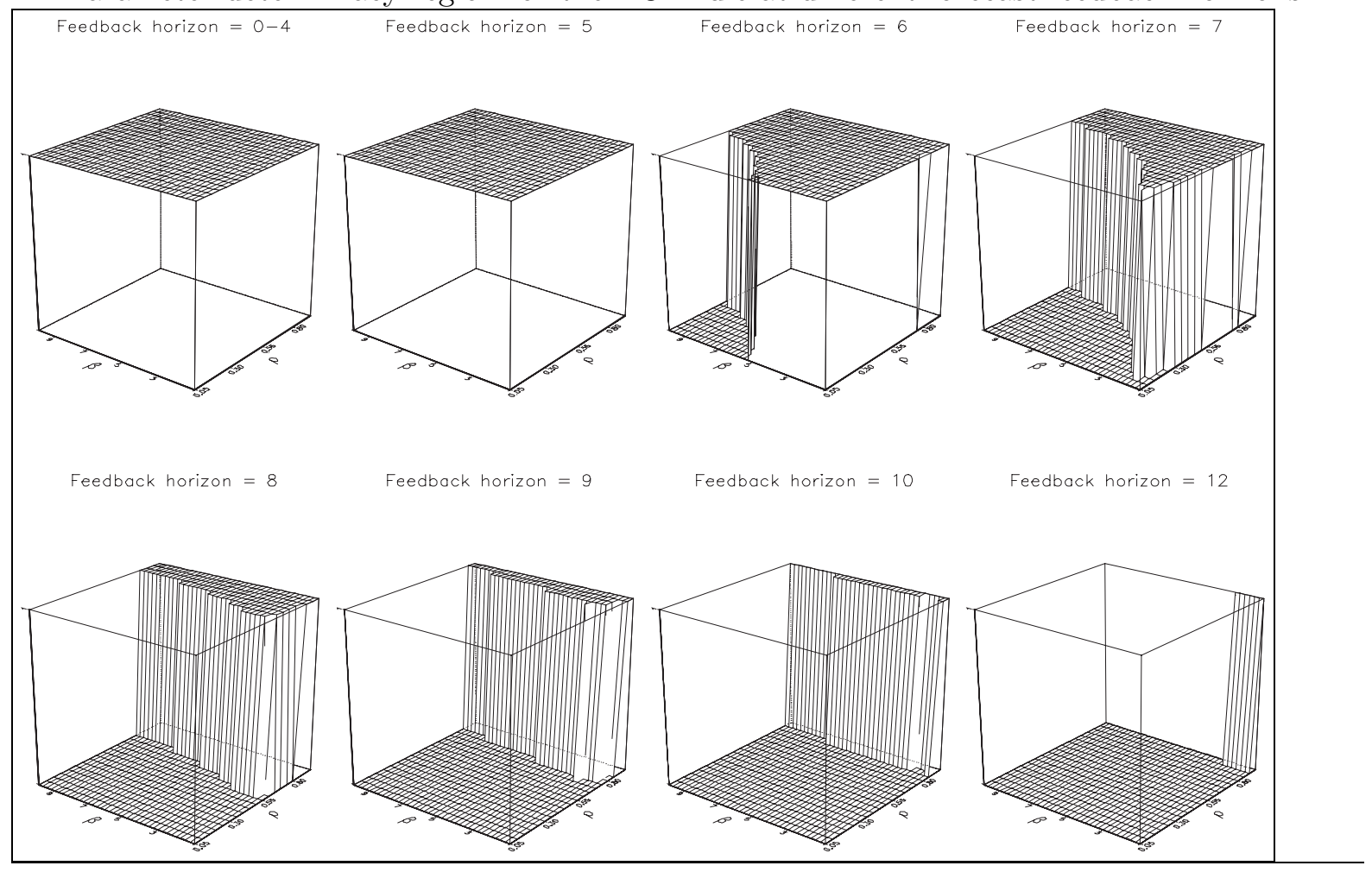

\subsection{Optimality}

The policymaker chooses the triplet $\left\{H, \beta, \rho_{r}\right\}$ so as to produce a determinate rational expectations equilibrium and minimize expected loss, as stated in equation (2). We use a grid-search over the values of the triplet that produce a determinate $\mathrm{RE}$ equilibrium with a mask-width of 0.05 for $\rho_{r}$ and 0.25 for $\beta_{\pi}$. We assume that the policymaker is a flexible inflation targeter that set $\lambda=0.50$ and $\nu=0.25$. The optimal coefficients at different horizons and the associated standard deviations and loss are presented in Table 1.

Several results are worth noting. First, we find that the optimal forecast-feedback horizon is between one and two years. The optimal horizon for the UIF rule is only a quarter shorter than the optimal horizon for the PCF rule. Moreover, the optimal coefficients and the properties for the two rules are very similar at short horizons. Given the high degree of inertia in the model, the difference between the assumption of a unchanged-interest-rate and policy-consistent inflation forecast is minor if the forecast-feedback horizon is relatively short. For horizons above seven quarters, there are important differences, however. The optimal coefficients are significantly different, with the policy-consistent rule being the most "active". The PCF rule weakly dominates the UIF rule at all horizons considered, and the consequences of a long forecast-targeting horizon are more severe for the UIF rule, with strong volatility in inflation and output. In this regards, the PCF rule is more robust than the UIF rule with respect to choosing a the forecast-feedback horizon as loss is more independent of this particular choice. 
Table 1

Unconditional standard deviations in per cent and losses. ${ }^{\text {a }}$

\begin{tabular}{|c|c|c|c|c|c|c|c|c|c|}
\hline$H$ & $\beta$ & $\rho_{r}$ & $\bar{\pi}$ & $x$ & $\Delta r$ & $q$ & $s$ & $L(.5, .25)$ & $L(.5, .1)$ \\
\hline \multicolumn{10}{|c|}{ UIF rule } \\
\hline 0 & 1.00 & 0.95 & 2.97 & 9.69 & 0.15 & 31.99 & 22.24 & 51.32 & 51.32 \\
\hline 1 & 1.00 & 0.95 & 3.02 & 9.68 & 0.14 & 32.01 & 22.26 & 51.39 & 51.39 \\
\hline 2 & 1.00 & 0.95 & 3.24 & 9.49 & 0.15 & 32.31 & 22.29 & 50.28 & 50.27 \\
\hline 3 & 1.00 & 0.95 & 3.68 & 9.16 & 0.15 & 32.85 & 22.33 & 48.73 & 48.73 \\
\hline 4 & 1.00 & 0.95 & 4.41 & 8.73 & 0.16 & 33.67 & 22.41 & 47.83 & 47.83 \\
\hline 5 & 2.75 & 0.35 & 3.18 & 8.91 & 2.51 & 32.32 & 22.01 & 46.38 & 45.43 \\
\hline *6 6 & 6.00 & 0.75 & 3.42 & 8.30 & 1.31 & 33.13 & 21.84 & 40.73 & 40.47 \\
\hline 7 & 6.25 & 0.90 & 3.32 & 8.44 & 0.79 & 32.94 & 21.83 & 41.32 & 41.23 \\
\hline 8 & 6.25 & 0.95 & 3.05 & 9.13 & 0.58 & 32.07 & 21.89 & 46.41 & 46.36 \\
\hline 9 & 1.00 & 0.30 & 7.15 & 7.91 & 0.54 & 37.13 & 21.69 & 56.85 & 56.81 \\
\hline 10 & 1.00 & 0.70 & 9.17 & 8.31 & 0.49 & 39.51 & 22.21 & 76.66 & 76.63 \\
\hline 11 & 1.00 & 0.40 & 25.59 & 22.47 & 0.75 & 57.77 & 27.72 & 579.94 & 579.85 \\
\hline 12 & 1.00 & 0.05 & 44.57 & 55.80 & 0.82 & 35.57 & 37.57 & 2550.21 & 2550.11 \\
\hline \multicolumn{10}{|c|}{ PCF rule } \\
\hline 0 & 1.00 & 0.95 & 2.97 & 9.69 & 0.15 & 31.99 & 22.24 & 51.32 & 51.32 \\
\hline 1 & 1.00 & 0.95 & 3.02 & 9.68 & 0.14 & 32.01 & 22.26 & 51.39 & 51.39 \\
\hline 2 & 1.00 & 0.95 & 3.24 & 9.49 & 0.15 & 32.31 & 22.29 & 50.28 & 50.27 \\
\hline 3 & 1.00 & 0.95 & 3.68 & 9.16 & 0.15 & 32.85 & 22.33 & 48.73 & 48.73 \\
\hline 4 & 1.00 & 0.95 & 4.41 & 8.73 & 0.16 & 33.67 & 22.41 & 47.82 & 47.82 \\
\hline 5 & 2.50 & 0.10 & 3.17 & 9.00 & 2.41 & 32.22 & 22.05 & 46.99 & 46.12 \\
\hline 6 & 4.50 & 0.10 & 3.42 & 8.28 & 2.30 & 33.09 & 21.83 & 41.42 & 40.63 \\
\hline$* 7$ & 8.75 & 0.65 & 3.55 & 8.10 & 0.98 & 33.44 & 21.83 & 39.35 & 39.21 \\
\hline 8 & 10.00 & 0.80 & 3.45 & 8.26 & 0.79 & 33.22 & 21.85 & 40.24 & 40.15 \\
\hline 9 & 8.25 & 0.85 & 3.17 & 8.79 & 0.66 & 32.52 & 21.87 & 43.73 & 43.67 \\
\hline 10 & 7.00 & 0.90 & 3.01 & 9.60 & 0.50 & 31.47 & 21.88 & 50.69 & 50.66 \\
\hline 11 & 7.50 & 0.95 & 3.93 & 11.04 & 0.49 & 29.74 & 21.80 & 68.78 & 68.75 \\
\hline 12 & 2.50 & 0.95 & 5.58 & 14.83 & 0.34 & 26.64 & 22.77 & 125.51 & 125.49 \\
\hline \multicolumn{10}{|c|}{ Optimal commitment rule $\lambda=0.50 \nu=0.25$} \\
\hline- & - & - & 4.90 & 5.70 & 3.26 & 36.60 & 21.19 & 30.9 & 29.30 \\
\hline \multicolumn{10}{|c|}{ Optimal commitment rule $\lambda=0.45^{b} \nu=0.10$} \\
\hline- & - & - & 4.77 & 5.58 & 4.36 & 36.70 & 21.05 & 31.68 & 28.82 \\
\hline
\end{tabular}

${ }^{\text {a }}$ First three columns show the optimal configuration for policy rule at different forecast-feedback horizons. The next five columns show the standard deviations of respective variables, and the last two columns show expected losses.

b The numerical routine fails to solve for the commitment policy equilibrium for $\lambda=0.50$ and $\nu=0.10$.

The optimal choice of coefficients involves considerable interest-rate inertia at most horizons, with $\rho_{r}$ being close to unity. The optimality of interest-rate inertia in forward-looking models is discussed in Woodford (2003). Such inertia, or history-dependence, influences private-sector expectations about the future as a given monetary-policy stance is expected to prevail. The ability to affect expectations about the future will enhance the central banks ability to influence private-sector behavior today because agents act in a forward-looking manner.

Inflation targeting is associated with extensive use of the exchange-rate channel. Real exchange-rate volatility is slightly smaller for the forecast-feedback rules compared to the optimal commitment policy, so the source of the volatility is not the forecast-feedback rules. It is 


\section{Figure 4}

The trade-off between inflation and output volatility under optimized UIF (left) and PCF (right) rules and the optimal commitment rule with $\lambda \in[0,1]$ and $\nu=0.25$.
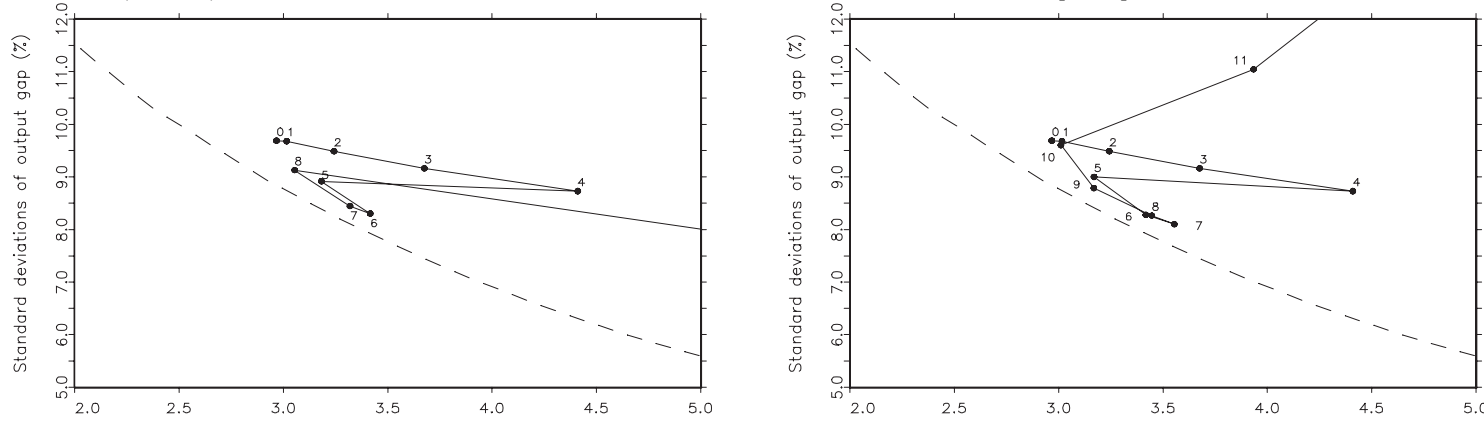

known that price stickiness on imported goods lead to more exchange-rate variability under inflation targeting (see Adolfson (2001)). The reason is that since prices are subject to stickiness, imported goods prices respond less to any shocks that cause a movement in the exchange rate. Hence, exchange rate stability is not such an important requirement for inflation and output stability as it is if prices on the imported goods are flexible.

Figure 4.3 shows the combinations of the standard deviations of inflation and output for the optimal forecast-feedback rules at different horizons, in addition to the optimal trade-off generated by the optimal commitment policy - referred to as the policy efficiency frontier. ${ }^{10}$

As is clear from Figure 4.3, the both policy rules are close to the policy efficiency frontier. Still, from Table 1 we see that the optimal forecast-feedback rules generate loss that are as much as 30 per cent worse than the optimal commitment policy. Reducing the weight on interestrate smoothing to $\nu=0.1$ have virtually no effect on this result. Relative to the optimal commitment policy, the forecast-feedback rules generate too much inflation stabilization and interest-rate smoothing, and too little output-gap stability. This result confirms and extends the result in Levin et al. (2001) for the relatively closed US economy who argue that the rule performance of the rule can be significantly improved is extended with a response to the output gap. In this regard, neither rules are as "output encompassing" as claimed by Batini and Haldane (1999).

In order to illustrate this even further, we can vary the weight on inflation and output stabilization in the loss function and see how this influences the choice of horizon and the efficiency of the policy rules. Table 2 shows the optimal horizon and loss relative to the optimal commitment policy for different configurations of $\lambda \in\{0.2,0.4,0.6,0.8\}$.

\footnotetext{
${ }^{10}$ The policy efficiency frontier is constructed by plotting the unconditional standard deviations of inflation and output generated by the optimal commitment policy when $\lambda$ varies between 0 and 1 .
} 
Table 2

Central bank preferences and optimal rule configurations. ${ }^{\text {a }}$

\begin{tabular}{|c|c|c|c|c|c|}
\hline$\lambda$ & $\beta$ & $\rho_{r}$ & $H$ & $L(\lambda, .25)$ & $L_{r}$ \\
\hline \multicolumn{6}{|c|}{ UIF rule } \\
\hline 0.2 & 6.25 & 0.90 & 7 & 23.23 & $2.07 \%$ \\
\hline 0.4 & 5.00 & 0.70 & 6 & 34.98 & $17.86 \%$ \\
\hline 0.6 & 7.75 & 0.80 & 6 & 46.43 & $48.67 \%$ \\
\hline 0.8 & 7.75 & 0.80 & 6 & 57.77 & $100.38 \%$ \\
\hline \multicolumn{6}{|c|}{ PCF rule } \\
\hline 0.2 & 4.25 & 0.45 & 7 & 23.14 & $1.67 \%$ \\
\hline 0.4 & 7.00 & 0.65 & 7 & 34.05 & $15.38 \%$ \\
\hline 0.6 & 8.75 & 0.65 & 7 & 44.65 & $42.97 \%$ \\
\hline 0.8 & 8.75 & 0.65 & 7 & 55.24 & $91.61 \%$ \\
\hline
\end{tabular}

We can see that both rules can bring the outcome close to the optimal commitment policy outcome if the central bank is relatively strict on inflation, loss being only 2.07 and 1.67 per cent worse for the two rules respectively. Efficiency of both rules, however, deteriorates very quickly as the relative weight on the output gap is increased. Interestingly, the optimal forecast-feedback horizon is robustly around one and a half year for both rules. The optimized coefficients remain more stable for the UIF rule and for the PCF rule as the weight is changed.

\section{Conclusion}

This paper has evaluated inflation forecast-feedback rules in an estimated, micro-founded model of the UK economy. We find that these rules are efficient in that they bring inflation and output close to the optimal policy inflation-output variance frontier. These rules are in general better at stabilizing inflation than output, as the output gap is considerably more volatile than in the optimal policy commitment equilibrium. The optimal forecast-feedback horizon is surprisingly stable at six or seven quarters, and independent of the weight the central bank attaches to inflation versus output stabilization. A potential problem with both forecast-feedback rules is that the rules do not necessarily ensure determinacy of the rational expectations equilibrium. This problem is especially acute at long forecast-feedback horizons where the set of rule parameters that brings determinacy is quite small.

We find that the forecast-feedback rule that using an unchanged-interest-rate forecast of inflation does in general decrease the parameter determinacy space, and does not improve on the performance of the rule. The implied dynamics of the rules do, however, differ importantly when the central bank applies a long forecast-feedback horizon. 


\section{Appendix}

\section{A. Analytical derivation of policy with the constant-interest-rate forecasts as the indicator}

This subsection derives the UIF policy in a general dynamic model. An important and large class of dynamic models can be set in the following state-space form:

$$
Z_{t+1}=A Z_{t}+B r_{t}+\varepsilon_{t+1}
$$

where $A$ is the companion matrix and $B$ is a vector of interest-rate impact multipliers; $Z$ is a vector of state variables. Using repeated substitutions, we can write the expected value of the state vector at time $t+h$ made at time $t$ as

$$
Z_{t+h \mid t}=A^{h} Z_{t}+\sum_{i=1}^{h} A^{h-i} B r_{t+i-1 \mid t} .
$$

Providing that the interest rate level in the previous period being kept throughout the forecast horizon, we may write the unchanged-interest-rate forecast as

$$
Z_{t+h \mid t}\left(\bar{r}_{t-1}\right)=A^{h} Z_{t}+\sum_{i=1}^{h} A^{h-i} B r_{t-1}
$$

Assume that the state vector includes the relevant variables so we can set

$$
\begin{aligned}
\bar{\pi}_{t} & \equiv K_{\pi} Z_{t}, \\
r_{t-1} & \equiv K_{r} Z_{t} .
\end{aligned}
$$

for appropriately defined $K_{\pi}$ and $K_{r}$. We can then insert (A3) and (A4) into (A2) to get the unchangedinterest-rate forecast of the four-quarter inflation rate as

$$
\begin{aligned}
\bar{\pi}_{t+h \mid t}\left(\bar{r}_{t-1}\right) & =K_{\pi} Z_{t+h \mid t}\left(\bar{r}_{t-1}\right) \\
& =K_{\pi} A^{h} Z_{t}+K_{\pi} \sum_{i=1}^{h} A^{h-i} B K_{r} Z_{t} .
\end{aligned}
$$

The inflation forecast feedback rule is given from (4),

$$
r_{t}=\rho_{r} r_{t-1}+\left(1-\rho_{r}\right) \beta_{\pi} \bar{\pi}_{t+h \mid t}\left(\bar{r}_{t-1}\right),
$$

where $\pi^{*}=0$. Using (A3), (A4) and (A5), this rule may be written as a function of the state vector as

$$
r_{t}=F Z_{t},
$$

where $F=\rho_{r} K_{r}+\left(1-\rho_{r}\right) \beta_{\pi} K_{\pi} A^{h}+\left(1-\rho_{r}\right) K_{\pi} \sum_{i=1}^{h} A^{h-i} B K_{r}$. 
If the state vector consists of both backward-looking, $z_{1, t}$, and forward-looking, $z_{2, t}$, variables, i.e., $Z_{t}=\left[\begin{array}{ll}z_{1, t} & z_{2, t}\end{array}\right]^{\prime}$, then the state space form in (A1) may be written as,

$$
\left[\begin{array}{c}
z_{1, t+1} \\
z_{2, t+1 \mid t}
\end{array}\right]=\left[\begin{array}{cc}
A_{11} & A_{12} \\
A_{21} & A_{22}
\end{array}\right]\left[\begin{array}{c}
z_{1, t} \\
z_{2, t}
\end{array}\right]+\left[\begin{array}{c}
B_{1} \\
B_{2}
\end{array}\right] r_{t}+\left[\begin{array}{c}
\varepsilon_{t+1} \\
0
\end{array}\right]
$$

The interest rate rule in (A6) may be written as $r=\left[\begin{array}{ll}F_{1} & F_{2}\end{array}\right]\left[\begin{array}{ll}z_{1, t} & z_{2, t}\end{array}\right]^{\prime}$. After inserting the interest rate rule in $(\mathrm{A} 7)$, we get

$$
\begin{aligned}
{\left[\begin{array}{c}
z_{1, t+1} \\
z_{2, t+1 \mid t}
\end{array}\right] } & =\left[\begin{array}{ll}
A_{11} & A_{12} \\
A_{21} & A_{22}
\end{array}\right]\left[\begin{array}{l}
z_{1, t} \\
z_{2, t}
\end{array}\right]+\left[\begin{array}{c}
B_{1} \\
B_{2}
\end{array}\right]\left[\begin{array}{ll}
F_{1} & F_{2}
\end{array}\right]\left[\begin{array}{c}
z_{1, t} \\
z_{2, t}
\end{array}\right]+\left[\begin{array}{c}
\varepsilon_{t+1} \\
0
\end{array}\right] \\
& =\left(\left[\begin{array}{cc}
A_{11} & A_{12} \\
A_{21} & A_{22}
\end{array}\right]+\left[\begin{array}{cc}
B_{1} F_{1} & B_{1} F_{2} \\
B_{2} F_{1} & B_{2} F_{2}
\end{array}\right]\right)\left[\begin{array}{c}
z_{1, t} \\
z_{2, t}
\end{array}\right]+\left[\begin{array}{c}
\varepsilon_{t+1} \\
0
\end{array}\right] \\
& =\left[\begin{array}{cc}
C_{11} & C_{12} \\
C_{21} & C_{22}
\end{array}\right]\left[\begin{array}{c}
z_{1, t} \\
z_{2, t}
\end{array}\right]+\left[\begin{array}{c}
\varepsilon_{t+1} \\
0
\end{array}\right]
\end{aligned}
$$

where the $C$-matrix is defined accordingly.

Blanchard and Kahn (1980) show that the rational expectations equilibrium is unique if the number of eigenvalues of $C$ outside the unit circle is equal to the number of forward-looking variables. The forward-looking variables may then be written as a linear function of the predetermined variables,

$$
z_{2, t}=H z_{1, t}
$$

The $H$ is a function of the underlying model coefficient and can be found by applying the techniques discussed Klein (2000) and Söderlind (1999).

Note that in equilibrium, the interest rate follows

$$
i_{t}=\left(F_{1}+F_{2} H\right) z_{1, t}
$$




\section{B. Analytical derivation of policy with the policy-consistent forecasts as the indicator}

See also Rudebusch and Svensson (1999, Appendix).

\section{B.1. The case of $H=4$}

We first use that

$$
\pi_{t+4 \mid t} \equiv e_{\pi, 3} Z_{t+1 \mid t}
$$

where $e_{\pi, j}$ is appropriately defined vectors so that $\pi_{t+j \mid t} \equiv e_{\pi, j} Z_{t}$. We then take expectations in equation (A1) and get $Z_{t+1 \mid t}=A Z_{t}+B r_{t}$. Furthermore, the PCF rule is given by

$$
r_{t}=\rho_{r} r_{t-1}+\left(1-\rho_{r}\right) \beta_{\pi} \frac{1}{4}\left(\pi_{t+4 \mid t}+\pi_{t+3 \mid t}+\pi_{t+2 \mid t}+\pi_{t+1 \mid t}\right) .
$$

By using the rule and the expression for $Z_{t+1 \mid t}$, we get

$$
\begin{aligned}
\pi_{t+4 \mid t} & =e_{\pi, 3}\left(A Z_{t}+B r_{t}\right) \\
& =e_{\pi, 3}\left(A Z_{t}+B\left(\rho_{r} r_{t-1}+\left(1-\rho_{r}\right) \beta_{\pi} \frac{1}{4}\left(\pi_{t+4 \mid t}+\pi_{t+3 \mid t}+\pi_{t+2 \mid t}+\pi_{t+1 \mid t}\right)\right)\right) \\
& =e_{\pi, 3}\left(A+B \rho_{r} e_{r}+B\left(1-\rho_{r}\right) \beta_{\pi} \frac{1}{4}\left(e_{\pi, 3}+e_{\pi, 2}+e_{\pi, 1}\right)\right) Z_{t}+e_{\pi, 3} B\left(1-\rho_{r}\right) \beta_{\pi} \frac{1}{4} \pi_{t+4 \mid t} . \\
& =\left(1-e_{\pi, 3} B\left(1-\rho_{r}\right) \beta_{\pi} \frac{1}{4}\right)^{-1} e_{\pi, 3}\left(A+B \rho_{r} e_{r}+B\left(1-\rho_{r}\right) \beta_{\pi} \frac{1}{4}\left(e_{\pi, 3}+e_{\pi, 2}+e_{\pi, 1}\right)\right) Z_{t}
\end{aligned}
$$

where $e_{r}$ is defined so that $r_{t-1}=e_{r} Z_{t}$.

The model can then be written with endogenous interest rate as

$$
\begin{aligned}
Z_{t+1 \mid t}= & A Z_{t}+B r_{t} \\
= & A Z_{t}+B\left(\rho_{r} r_{t-1}+\left(1-\rho_{r}\right) \beta_{\pi} \frac{1}{4}\left(\pi_{t+4 \mid t}+\pi_{t+3 \mid t}+\pi_{t+2 \mid t}+\pi_{t+1 \mid t}\right)\right) \\
= & \left(A+B \rho_{r} e_{r}+B\left(1-\rho_{r}\right) \beta_{\pi} \frac{1}{4}\left(e_{\pi, 3}+e_{\pi, 2}+e_{\pi, 1}\right)\right) Z_{t} \\
& +B\left(1-\rho_{r}\right) \beta_{r} \frac{1}{4}\left(1-e_{\pi, 3} B\left(1-\rho_{r}\right) \beta_{r} \pi \frac{1}{4}\right)^{-1} e_{\pi, 3}\left(A+B \rho_{r} e_{r}+B\left(1-\rho_{r}\right) \beta_{\pi} \frac{1}{4}\left(e_{\pi, 3}+e_{\pi, 2}+e_{\pi, 1}\right)\right) Z_{t}
\end{aligned}
$$

Hence,

$$
Z_{t+1 \mid t}=\tilde{A} Z_{t}
$$

and

$$
Z_{t+1}=\tilde{A} Z_{t}+V_{t+1}
$$


where

$$
\begin{aligned}
\tilde{A} \equiv & A+B \rho_{r} e_{r}+B\left(1-\rho_{r}\right) \beta_{\pi} \frac{1}{4}\left(e_{\pi, 3}+e_{\pi, 2}+e_{\pi, 1}\right) \\
& +B\left(1-\rho_{r}\right) \beta_{\pi} \frac{1}{4}\left(1-e_{\pi, 3} B\left(1-\rho_{r}\right) \beta_{\pi} \frac{1}{4}\right)^{-1} e_{\pi, 3}\left(A+B \rho_{r} e_{r}+B\left(1-\rho_{r}\right) \beta_{\pi} \frac{1}{4}\left(e_{\pi, 3}+e_{\pi, 2}+e_{\pi, 1}\right)\right)
\end{aligned}
$$

\section{B.2. The case of $H>4$}

We note that

$$
\begin{aligned}
\pi_{t+4 \mid t} & =e_{\pi, 3} Z_{t+1 \mid t} \\
& =e_{\pi, 3}\left(A Z_{t}+B r_{t}\right) \\
& =e_{\pi, 3} A Z_{t}+e_{\pi, 3} B\left(\rho_{r} r_{t-1}+\left(1-\rho_{r}\right) \beta_{\pi} \frac{1}{4}\left[\pi_{t+H \mid t}+\pi_{t+H-1 \mid t}+\pi_{t+H-2 \mid t}+\pi_{t+H-3 \mid t}\right]\right) \\
& =e_{\pi, 3}\left(A+B \rho_{r} e_{r}\right) Z_{t}+e_{\pi, 3} B\left(1-\rho_{r}\right) \beta_{\pi} \frac{1}{4} \pi_{t+H \mid t}+e_{\pi, 3} B\left(1-\rho_{r}\right) \beta_{\pi} \frac{1}{4}\left(\pi_{t+H-1 \mid t}+\pi_{t+H-2 \mid t}+\pi_{t+H-3 \mid t}\right)
\end{aligned}
$$

and thus

$$
e_{\pi, 3} B\left(1-\rho_{r}\right) \beta_{\pi} \frac{1}{4} \pi_{t+H \mid t}=\pi_{t+4 \mid t}-e_{\pi, 3}\left(A+B \rho_{r} e_{r}\right) Z_{t}-e_{\pi, 3} B\left(1-\rho_{r}\right) \beta_{\pi} \frac{1}{4}\left(\pi_{t+H-1 \mid t}+\pi_{t+H-2 \mid t}+\pi_{t+H-3 \mid t}\right)
$$

and therefore

$$
\begin{aligned}
\pi_{t+H \mid t}= & -\left(e_{\pi, 3} B\left(1-\rho_{r}\right) \beta_{\pi} \frac{1}{4}\right)^{-1}\left[\begin{array}{c}
e_{\pi, 3}\left(A+B \rho e_{r}\right) Z_{t} \\
+e_{\pi, 3} B\left(1-\rho_{r}\right) \beta_{\pi} \frac{1}{4}\left(\pi_{t+H-1 \mid t}+\pi_{t+H-2 \mid t}+\pi_{t+H-3 \mid t}\right)-\pi_{t+4 \mid t}
\end{array}\right] \\
= & -\left(e_{\pi, 3} B\left(1-\rho_{r}\right) \beta_{\pi} \frac{1}{4}\right)^{-1} e_{\pi, 3}\left(A+B \rho_{r} e_{r}\right) Z_{t}+\left(e_{\pi, 3} B\left(1-\rho_{r}\right) \beta_{\pi} \frac{1}{4}\right)^{-1} \pi_{t+4 \mid t} \\
& -\left(\pi_{t+H-1 \mid t}+\pi_{t+H-2 \mid t}+\pi_{t+H-3 \mid t}\right)
\end{aligned}
$$

The basis model in state-space is given as

$$
Z_{t+1}=A Z_{t}+B r_{t}+V_{t+1}
$$


and with the rule and the expression for $\pi_{t+H \mid t}$ inserted,

$$
\begin{aligned}
& Z_{t+1 \mid t}=A Z_{t}+B\left(\rho_{r} r_{t-1}+\left(1-\rho_{r}\right) \beta_{\pi} \frac{1}{4}\left[\pi_{t+H \mid t}+\pi_{t+H-1 \mid t}+\pi_{t+H-2 \mid t}+\pi_{t+H-3 \mid t}\right]\right) \\
& =\left(A+B \rho_{r} e_{r}\right) Z_{t}-B\left(1-\rho_{r}\right) \beta_{\pi} \frac{1}{4}\left(\begin{array}{l}
\left(e_{\pi, 3} B\left(1-\rho_{r}\right) \beta_{\pi} \frac{1}{4}\right)^{-1} e_{\pi, 3}\left(A+B \rho_{r} e_{r}\right) Z_{t} \\
+\left(\pi_{t+H-1 \mid t}+\pi_{t+H-2 \mid t}+\pi_{t+H-3 \mid t}\right)-\left(e_{\pi, 3} B\left(1-\rho_{r}\right) \beta_{\pi} \frac{1}{4}\right)^{-1} \pi_{t+4 \mid t}
\end{array}\right) \\
& +B\left(1-\rho_{r}\right) \beta_{\pi} \frac{1}{4}\left[\pi_{t+H-1 \mid t}+\pi_{t+H-2 \mid t}+\pi_{t+H-3 \mid t}\right] \\
& =\left(A+B \rho_{r} e_{r}-B\left(1-\rho_{r}\right) \beta_{\pi} \frac{1}{4}\left(e_{\pi, 3} B\left(1-\rho_{r}\right) \beta_{\pi} \frac{1}{4}\right)^{-1} e_{\pi, 3}\left(A+B \rho_{r} e_{r}\right)\right) Z_{t} \\
& -B\left(1-\rho_{r}\right) \beta_{\pi} \frac{1}{4}\left(\pi_{t+H-1 \mid t}+\pi_{t+H-2 \mid t}+\pi_{t+H-3 \mid t}\right) \\
& \left.+B\left(1-\rho_{r}\right) \beta_{\pi} \frac{1}{4}\left[\pi_{t+H-1 \mid t}+\pi_{t+H-2 \mid t}+\pi_{t+H-3 \mid t}\right]\right) \\
& +B\left(1-\rho_{r}\right) \beta_{\pi} \frac{1}{4}\left(e_{\pi, 3} B\left(1-\rho_{r}\right) \beta_{\pi} \frac{1}{4}\right)^{-1} \pi_{t+4 \mid t} \\
& =\left(A+B \rho_{r} e_{r}-B\left(1-\rho_{r}\right) \beta_{\pi} \frac{1}{4}\left(e_{\pi, 3} B\left(1-\rho_{r}\right) \beta_{\pi} \frac{1}{4}\right)^{-1} e_{\pi, 3}\left(A+B \rho_{r} e_{r}\right)\right) Z_{t} \\
& +B\left(1-\rho_{r}\right) \beta_{\pi} \frac{1}{4}\left(e_{\pi, 3} B\left(1-\rho_{r}\right) \beta_{\pi} \frac{1}{4}\right)^{-1} \pi_{t+4 \mid t}
\end{aligned}
$$

The expanded model is the basis model augmented by forward-looking variables representing the forecasts at different horizons. The augmented vector of variables are given as

$$
\begin{aligned}
& {\left[\begin{array}{c}
Z_{t+1} \\
\pi_{t+5 \mid t} \\
\ldots \\
\pi_{t+H-2 \mid t} \\
\pi_{t+H-1 \mid t} \\
\pi_{t+H \mid t}
\end{array}\right]=\left[\begin{array}{cccccc}
A_{11} & A_{12} & 0 & 0 & 0 & 0 \\
0 & 0 & 1 & 0 & 0 & 0 \\
0 & 0 & 0 & I & 0 & 0 \\
0 & 0 & 0 & 0 & 1 & 0 \\
0 & 0 & 0 & 0 & 0 & 1 \\
A_{61} & A_{62} & 0 & -1 & -1 & -1
\end{array}\right]\left[\begin{array}{c}
Z_{t} \\
\pi_{t+4 \mid t} \\
\cdots \\
\pi_{t+H-3 \mid t} \\
\pi_{t+H-2 \mid t} \\
\pi_{t+H-1 \mid t}
\end{array}\right] } \\
A_{11} & =\left(A+B \rho_{r} e_{r}-B\left(1-\rho_{r}\right) \beta_{\pi} \frac{1}{4}\left(e_{\pi, 3} B\left(1-\rho_{r}\right) \beta_{\pi} \frac{1}{4}\right)^{-1} e_{\pi, 3}\left(A+B \rho_{r} e_{r}\right)\right) \\
A_{12}= & B\left(1-\rho_{r}\right) \beta_{\pi} \frac{1}{4}\left(e_{\pi, 3} B\left(1-\rho_{r}\right) \beta_{\pi} \frac{1}{4}\right)^{-1} \\
A_{61}= & -\left(e_{\pi, 3} B\left(1-\rho_{r}\right) \beta_{\pi} \frac{1}{4}\right)^{-1} e_{\pi, 3}\left(A+B \rho_{r} e_{r}\right) \\
A_{62}= & \left(e_{\pi, 3} B\left(1-\rho_{r}\right) \beta_{\pi} \frac{1}{4}\right)^{-1}
\end{aligned}
$$




\section{Additional Figures}

Figure C1

The response to an unexpected reduction in the inflation target under PCF rule policy with $H=8, \rho=0.95$ and $\beta=6.25$.

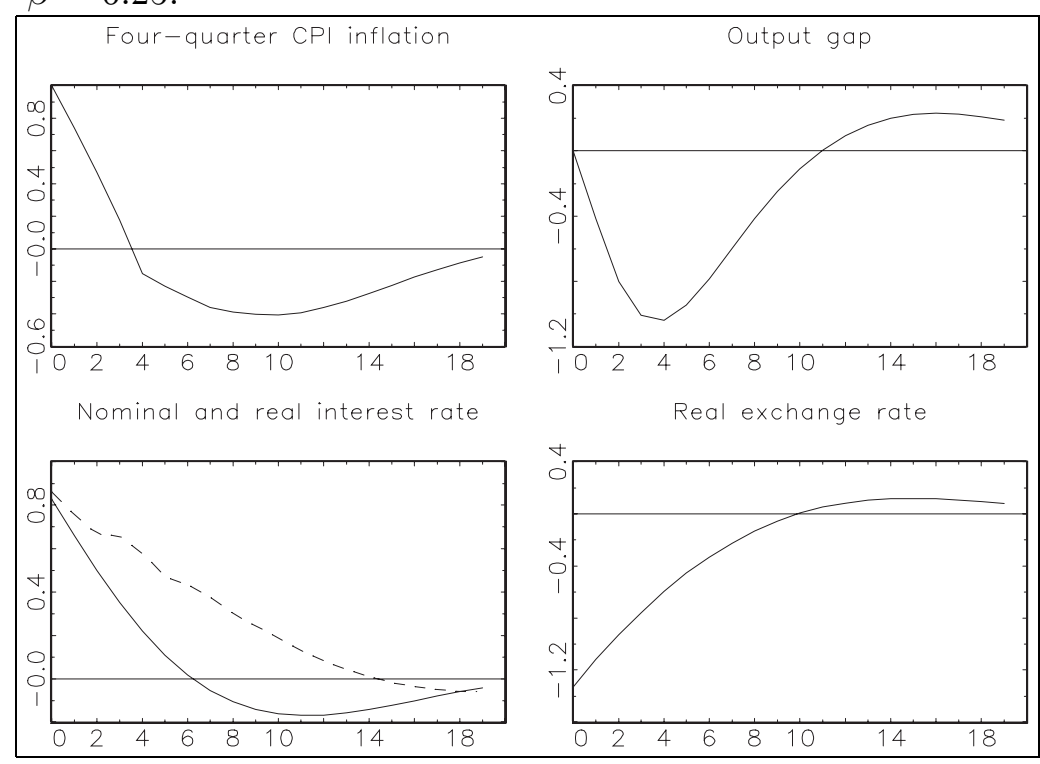




\section{References}

Adolfson, Malin (2001). "Monetary Policy with Incomplete Exchange Rate Pass-Through." Sveriges Riksbank Working Paper No. 127.

Batini, Nicoletta and Andrew Haldane (1999). "Forward-Looking Rules for Monetary Policy." In John B. Taylor (ed.), "Monetary Policy Rules," chap. 4, pp. 157-201. The University of Chicago Press, Chicago.

Batini, Nicoletta and Edward Nelson (2001). "Optimal Horizons for Inflation Targeting." Journal of Economic Dynamics and Control, 25:6-7:891-910.

Blanchard, Olivier Jean and Charles M. Kahn (1980). "The Solution of Linear Difference Models under Rational Expectations." Econometrica, 48:5:1305-11.

Calvo, Guillermo A. (1983). "Staggered Prices in a Utility-Maximizing Framework." Journal of Monetary Economics, 12(3):383-98.

Christiano, Lawrence J., Martin Eichenbaum, and Charles Evans (2001). "Nominal Rigidities and the Dynamic Effects of a Shock to Monetary Policy." NBER Working Paper 8403.

Fuhrer, Jeffrey C. (2000). "Habit Formation in Consumption and Its Implications for MonetaryPolicy Models." American Economic Review, 90 (3):367-90.

Gjedrem, Svein (2002). "Inflation Targeting in an Oil Economy." Speech at Sparebanken Møre, Ålesund.

Hansen, Lars Petter and Thomas J. Sargent (2003). "Robust Control and Economic Model Uncertainty." Manuscript, Stanford University.

Jansson, Per and Anders Vredin (2000). "Forecast-Based Monetary Policy in Sweden 1992-1998: A Transparent Analysis." Manuscript Sveriges Riksbank.

Klein, Paul (2000). "Using the Generalized Schur Form to Solve a Multivariate Linear Rational Expectations Model." Journal of Economic Dynamics and Control, 24:10:1405-23.

Leitemo, Kai (2000). "Open-Economy Inflation Forecast Targeting." Norges Bank Arbeidsnotat $2 / 2000$.

Levin, Andrew, Volker Wieland, and John C. Williams (2001). "The Performance of ForecastBased Monetary Policy Rules under Model Uncertainty." Forthcoming, American Economic Review. 
Monacelli, Tommaso (2003). "Monetary Policy in a Low Pass-Through Environment." Manuscript, IGIER, Universita' Bocconi. March 2003.

Rudebusch, Glenn (2002a). "Term Structure Evidence on Interest Rate Smoothing and Monetary Policy Inertia." Journal of Monetary Economics, 49:1161-1187.

Rudebusch, Glenn and Lars E.O. Svensson (1999). "Policy Rules for Inflation Targeting." In John B. Taylor (ed.), "Monetary Policy Rules," chap. 5, pp. 203-262. University of Chicago Press, Chicago.

Rudebusch, Glenn D. (2002b). "Assessing Nominal Income Rules for Monetary Policy with Model and Data Uncertainty." Economic Journal, 112:1-31.

Söderlind, Paul (1999). "Solution and Estimation of RE Macromodels with Optimal Policy." European Economic Review, 43(4-6):813-23.

Svensson, Lars E.O. (1997). "Inflation Forecast Targeting: Implementing and Monitoring Inflation Targets." European Economic Review, 41:1111-1146.

— (1999a). "Inflation Targeting as a Monetary Policy Rule." Journal of Monetary Economics, 43:3:607-654.

- (1999b). "Monetary Policy Issues for the Eurosystem." Carnegie-Rochester Conference Series on Public Policy, 51:1:79-136.

- (2000). "Open-Economy Inflation Targeting." Journal of International Economics, 50:155183.

Svensson, Lars E.O. and Michael Woodford (1999). "Implementing Optimal Policy Through Inflation-Forecast Targeting." Working paper, Department of Economics, Princeton University.

Sveriges Riksbank (1999). Inflation Report no. 3. Sveriges Riksbank.

Woodford, Michael (2001). "The Taylor Rule and Optimal Monetary Policy." American Economic Review, 91 (2):232-37.

— (2003). "Optimal Interest-Rate Smoothing." Review of Economic Studies, 70 (4):861-86. 